\title{
Entrevista: Bernard Lahire ${ }^{1}$
}

\section{CINARA LERRER ROSENFIELD \\ ALAN QUEIROZ \\ DIEGO MONTE BLANCO MATHILDE MONDON NAUAZO}

Entre os dias 24 e 25 de Novembro de 2011, o sociólogo Bernard Lahire, professor da École Normale Supérieure de Lyon, ministrou o curso Problemas e métodos de uma sociologia disposicional e contextualista para docentes e discentes integrantes do Programa de Pós-Graduação em Sociologia da UFRGS. Naquela ocasião, o mesmo concedeu uma entrevista que oportunizou, de modo complementar ao curso, uma melhor compreensão de algumas de suas contribuições teóricas e metodológicas para as Ciências Sociais. As questões que lhe foram colocadas visaram, primeiramente, informações sobre a trajetória intelectual do autor assim como definições conceituais a respeito de sua proposta teórica no que

\footnotetext{
${ }^{1}$ Tradução de Patrícia C.R. Reuillard (UFRGS).

* Doutora pela Université Paris Dauphine, Professora do Departamento e Programa de Pós-Graduação de Sociologia da UFRGS.

${ }^{* *}$ Mestre em Sociologia pela Universidade Federal do Rio Grande do Sul e Doutorando em Sociologia pela Universidade de Gante (Bélgica).

"** Doutorando em Sociologia pela Universidade Federal do Rio Grande do Sul, Professor do Instituto Federal do Rio Grande do Sul.

${ }^{* * * *}$ Doutoranda em Sociologia (cotutela) pela Universidade Federal do Rio Grande do Sul e em Economia pela Universidade Paris III Sorbonne Nouvelle (França).
} 
tange a compreensão da sociedade em escala individual. Tópicos diversos foram abordados, tais como o objeto da reflexividade, o senso prático da ação, a questão da identidade, bem como temas clássicos como a relação entre o indivíduo, instituições e sociedade. Além disso, abordou-se a sua avaliação sobre algumas proposições teóricas em voga na sociologia contemporânea. A entrevista a seguir deixa escapar um sociólogo bem-humorado, que não poupa a crítica a outros consagrados teóricos no campo das Ciências Sociais e nos remete constantemente à dimensão histórica dos fenômenos sociais. O grupo de trabalho que organizou e conduziu esta entrevista foi composto pela professora Cinara Lerrer Rosenfield e pelos discentes Allan Souza Queiroz (mestrando), Diego Monte Blanco e Mathilde Mondon Navazo (doutorandos), sendo que a entrevista foi revisada por Bernard Lahire antes da sua traduação. Nossos agradecimentos à Mathilde Mondon Navazo pela transcrição da entrevista e a Patrícia C. R. Reuillard pela tradução da entrevista ao português.

P: Vamos começar com uma pergunta sobre o início de sua carreira de sociólogo. O senhor poderia contar como se formou o Grupo de Pesquisas sobre a Socialização e falar dos primeiros trabalhos que fez com esse grupo?

B.L.: Comecei meus estudos superiores em 1981, na Universidade de Lyon 2, na França. Esse grupo já existia desde 1976 e reunia quase todos os sociólogos dessa Universidade. Os pesquisadores líderes desse grupo trabalhavam essencialmente sobre questões escolares: revisitavam a história da instituição escolar, estudavam as pequenas escolas rurais do Antigo Regime, analisavam as variantes da forma escolar surgidas entre os séculos $\mathrm{XVII}$ e XX, etc. Depois, progressivamente, os pesquisadores começaram a trabalhar no que se chamou de extensão da forma escolar de aprendizagem: perceberam que essa forma escolar se reproduzia nas formações 
profissionais e também que desempenhava um papel nas famílias de classe média e alta, na construção de uma relação pedagógica com a criança.

Nesse universo científico, eu me interessei pelas questões ligadas ao fracasso escolar nos meios populares. Enquanto todo esse grupo trabalhava com a escola, a aprendizagem escolar, o saber escolar, a relação do professor com os alunos na escola moderna, o que me interessava era ver que relação as crianças de meios populares tinham com essa forma escolar de aprendizagem, para tentar compreender suas dificuldades escolares. Além disso, estabeleci como foco da questão escolar o fato de se tratar de um lugar fundado em saberes escritos, objetivados.

Na época, havia os trabalhos de Bourdieu e Passeron sobre a reprodução, de Baudelot e Establet sobre a escola capitalista na França, etc. Mas havia também uma falta de compreensão sobre o que se passava realmente nas aulas para entender como se construía o fracasso escolar das crianças. Então, em meados dos anos 1980, trabalhei com essas questões de fracasso escolar na escola primária francesa.

P: Desde então, quais foram seus principais temas de estudo? Poderia dizer qual seu tema de estudo atual?

B.L.: Minha trajetória científica foi a de um sociólogo da educação e da cultura voltado às grandes questões das Ciências Humanas e Sociais. Comecei, portanto, trabalhando com o fracasso escolar na escola primária, tema de minha tese, defendida em 1990. Depois, sucessivamente, estudei os usos sociais da escrita, os sucessos escolares improváveis em meio popular, os estilos de estudo em diferentes áreas do ensino superior francês, a escalada (do fim dos anos 1970 ao fim dos anos 1990) dos discursos públicos sobre o "analfabetismo funcional", as práticas culturais dos franceses e, mais recentemente, a condição social dos escritores e os processos de criação literária, dando uma atenção mais particular ao uni- 
Sociologias, Porto Alegre, ano 17, no 38, jan/abr 2015, p. 280-302

verso de Franz Kafka ${ }^{1}$ que penetra os mistérios da dominação e desvela a magia de seus efeitos.

Também publiquei regularmente reflexões sobre questões de ordem epistemológica, teórica e metodológica em obras pessoais ou coletivas que levantavam questões como: "Que teoria da ação e do ator deve-se elaborar para explicar as práticas em um mundo social altamente diferenciado?"; "Como as Ciências Sociais podem pensar os fenômenos cognitivos?"; "O que caracteriza a epistemologia das Ciências Sociais?"; ou ainda, "Para que serve a Sociologia?". Esses trabalhos empíricos e essas reflexões culminaram na formulação de uma teoria da ação disposicionalista e contextual, sensível à escala individual do mundo social, que contribui para transformar a teoria do habitus e dos campos, desenvolvida por Bourdieu.

Atualmente, estudo a trajetória histórica de um quadro de Nicolas Poussin (pintor francês do século XVII, mestre do classicismo, cuja carreira se desenvolveu essencialmente em Roma). Embora pareça um objeto bastante estranho, ele não me afasta das questões que tratei até agora - dominações, crenças, legitimidade, peso da história, etc. - e permite dar conta da complexidade dos fatos sociais no cruzamento da sociologia da arte, das ciências, do direito, da economia e das instituições políticas.

P.: No que diz respeito à sociologia francesa em geral, Frédéric Vandenberghe distingue três correntes que exercem uma influência sobre a sociologia atual na França: Pierre Bourdieu e a sociologia crítica, Luc Boltanski e Laurent Thévenot e a sociologia pragmática e Bruno Latour e Michel Callon e a sociologia das redes sociotécnicas. O senhor aprova o recorte proposto por esse autor?O que pensa do panorama atual da sociologia francesa?

'LAHIRE, B.. Franz Kafka. Eléments pour une théorie de la création littéraire. Paris: La Découverte, Textes à l'appui/Laboratoire des sciences sociales, 2010. 
Sociologias, Porto Alegre, ano 17, o 38, jan/abr 2015, p. 280-302

B.L.: Pois bem, como não me encontro nessa classificação, fico muito chateado com o recorte proposto por Vandenberghe! [risos]. Brincadeiras à parte, existem outras correntes, e isso não é tão simples assim. É uma questão bastante complicada, porque é muito difícil dizer, em poucas palavras, o que penso desses autores. Evidentemente, não me reconheço na maioria das correntes anteriores, mas mantenho relações diferentes com cada uma delas... Por exemplo, não sou um grande fã do trabalho de Bruno Latour, simplesmente porque acho que ele não é suficientemente sério nem empiricamente, nem mesmo do ponto de vista argumentativo. Na sociologia francesa, ele é bastante provocador e então seduz muitas pessoas que apreciam o tipo de objeto que ele estuda. Ele também seduz porque deixa a sociologia dita "clássica" (resumindo, a que vai de Durkheim a Bourdieu,), mas não acho isso muito sério. Para ser mais exato, eu separaria trabalhos sérios, como A Vida de Laboratório², por exemplo, de trabalhos ou reflexões que me parecem um pouco mais estranhos.

Quanto a Boltanski e Thévenot, tenho críticas à sua abordagem e seus trabalhos (que por muito tempo negligenciaram a questão da dominação e esquecem o peso ou a força da história, tanto incorporada quanto objetivada), mas seria muito demorado expor aqui todas as razões que me levam a me distanciar.

Como ficou claro, foi sobretudo a corrente de Bourdieu, essencialmente sua obra, que me interessaram. Ao mesmo tempo, não fui um discípulo de Bourdieu. Ele é uma espécie de saco de pancada para mim: treino com ele, mas como em um ringue de boxe: eu bato! Venho dessa tradição, portanto, mas, quem diz Bourdieu diz, ao mesmo tempo, uma tradição durkheimiana, weberiana, com elementos de Marx, etc. Bour-

${ }^{2}$ LATOUR, B. ; WOOLGAR, S. (1979), La vie de laboratoire. La production des faits scientifiques, rééd. La Découverte, coll. "Poche", 2006. LATOUR, Bruno; WOOLGAR, Steve. 1997. A vida de laboratório: a produção dos fatos científicos. (Trad. Angela R. Vianna) Rio de Janeiro: Relume Dumará. 1988. 
Sociologias, Porto Alegre, ano 17, no 38, jan/abr 2015, p. 280-302

dieu integrou inúmeras teorias diferentes em sua sociologia. A meu ver, é a sociologia mais rica dessa geração, e é na continuidade desse modelo que tento desenvolver criticamente minha própria linha de pesquisa.

De maneira geral, acredito que o estado atual da sociologia francesa não é extraordinário. Não há muito desejo de debater e, frequentemente, tenho a impressão de debater sozinho, mas minha convicção é tal que sigo sozinho. Assim como as pessoas idosas que falam sozinhas, eu continuo... [risos]. Então, dialogo, debato, critico em meus livros, mas há poucas respostas, poucos diálogos, poucos debates. Será que houve um dia? Acredito que, nas décadas de sessenta e setenta, na França, os debates eram mais acirrados, com oposições muito claras. Nos dias de hoje, vê-se uma espécie de "jogo de massacre" da obra de Pierre Bourdieu: todo mundo tenta criticá-lo, mas me parece que não no sentido positivo. De certo modo, evita-se lê-lo, dispensam-se os estudantes de lê-lo, dizendo: "Mas isso é a velha sociologia, é sociologia clássica!" Que estupidez! Em Le Travail sociologique de Pierre Bourdieu, afirmei que era um suicídio descartar esse trabalho. Os pesquisadores que fazem isso dão um tiro no próprio pé. Seria o mesmo que dizer, no fim do século XIX ou no início do século XX: "Não, não, Durkheim não me interessa". Se Durkheim não me interessa, posso trabalhar com Música, Linguística ou Engenharia, mas não posso pretender trabalhar com Sociologia sem ler Durkheim, sem criticar Durkheim, sem discutir sobre seu trabalho.

Acho então que há uma falta coletiva de debate, de vontade crítica, de argumentação, de contra-argumentação. Uma vida intelectual saudável é uma vida em que os pesquisadores respondem com seus trabalhos, criticam a argumentação dos outros e fazem seus leitores ganharem tempo e dizerem: "Ah, sim, este argumento é melhor do que aquele e se pode avançar". É assim que concebo o debate científico, mas hoje exis-

${ }^{3}$ LAHIRE, B.. Le travail sociologique de Pierre Bourdieu. La Découverte, coll. “Poche”, 2001. 
tem, sobretudo projetos paralelos que não dialogam. Não acho isso muito saudável cientificamente.

P.: Na obra Homem Plural ${ }^{4}$, o senhor menciona um certo tipo de reflexividade que os indivíduos podem exercer no mundo atual - a reflexividade sobre suas práticas. Essa reflexividade seria possível, em inúmeros momentos da vida cotidiana, graças à experiência dos atores em diferentes contextos de socialização, principalmente graças a experiências concorrentes e contraditórias em termos de valores, de comportamentos. Os atores poderiam apresentar um grau de reflexividade maior ou menor sobre suas práticas e seus espaços de socialização, em função do nível ou da intensidade desse contraste ou em função das crises às quais são confrontados nessa heterogeneidade socializadora.

Outros autores abordam o tema da reflexividade, estabelecendo um vínculo entre esta e a possibilidade de uma análise da ação dos atores sociais, ou dos efeitos da ação no mundo contemporâneo. Giddens, por exemplo, analisa a reflexividade principalmente através de uma correlação entre conceitos de segurança, de rotina e de consciência prática versus incerteza, risco e outros elementos da modernidade tardia. Já Dubet propõe uma relação conflitiva na construção do ego; ele demonstra a existência de uma reflexividade a partir da experiência conflitiva do ator devido à relação entre espaços institucionais mais tradicionais, sua experiência no mercado e a promessa de individuação da modernidade. Gostaríamos de saber sua opinião sobre esse objeto, "a reflexividade", nas análises propostas por esses autores.

${ }^{4}$ LAHIRE, B.. L'homme pluriel. Les ressorts de l'action. Nathan, coll. Essais \& Recherches, Sciences sociales, 1998. LAHIRE, Bernard. Homem plural: os determinantes da ação. Tradução de: Jaime A. Clasen. Petrópolis: Vozes, 2002. 
Sociologias, Porto Alegre, ano 17, oo 38, jan/abr 2015, p. 280-302

B.L.: Vou responder de um modo rápido e radical: não sei se Anthony Giddens é um sociólogo. É muito duro dizer isso assim, mas, de meu ponto de vista, ele é mais um teórico do social. Tenho a impressão de não fazer parte do mesmo mundo científico que Giddens. Penso que é outro mundo, o de pessoas que refletem abstratamente sobre a realidade, que não fazem investigações; para mim, são filósofos. Posso achar interessantes os textos de Giddens, mas muitas vezes o que acho interessante em seu trabalho encontro também em outros autores - como Bourdieu - que, por outro lado, fizeram pesquisas empíricas. Existem afinidades entre Giddens e Bourdieu: quando se costuma ler Bourdieu, "agência", "estrutura", "reflexividade" ou "senso prático" são noções familiares. Mas Giddens não é um autor empírico e, se minha resposta pode acabar com o complexo de quem não tem vontade de ler Giddens, ficarei bem contente! Mas é claro que se pode lê-lo. Pessoalmente, leio Foucault, leio filósofos como Wittgenstein ou Merleau-Ponty. Não são sociólogos, mas eu os leio pelo trabalho de esclarecimento que eles fazem em relação a questões conceituais. Não estou certo que Giddens me auxilie a esclarecer problemas. Prefiro, em última instância, filósofos analíticos que selecionam problemas e os esclarecem.

Abordei a questão da reflexividade a partir de objetos empíricos bem comuns. Às vezes, meus colegas me olhavam de um jeito esquisito porque eu trabalhava com listas de compras, bilhetes, lembretes, todas essas pequenas escritas ordinárias, na vida doméstica ou na vida profissional. Essas escritas são, com efeito, espécies de rupturas em relação ao senso prático; escrevemos justamente para fazer uma espécie de pausa na ação e para planejá-la. Em uma família, por exemplo, as listas de compras, frequentemente feitas pelas mulheres, são planejamentos - é preciso comprar isso e aquilo - organizados por corredor, por seção, etc. São pequenos instrumentos de reflexividade diária, de planejamento da ação, que fazem ganhar tempo e evitam os esquecimentos, como o uso do calendário ou da agenda. 
Sociologias, Porto Alegre, ano 17, o 38, jan/abr 2015, p. 280-302

É o caso também das pessoas que telefonam a uma repartição pública e escrevem antes o que vão dizer para não esquecer um dado ou outro: são espécies de preparações retóricas do que elas vão dizer, porque é difícil conseguir uma ligação com uma repartição, porque se prefere não ter que telefonar de novo, etc. As pessoas tomam notas para dizer "Bem, vou precisar perguntar isso, isso e aquilo", e preparam seu discurso.

Tudo isso é reflexividade, são momentos de reflexividade. O que reprovo nos debates que ocorrem na Sociologia, e que a meu ver são mais debates filosóficos e às vezes até morais, é que se tenta resolver essa questão de maneira abstrata. Os atores são reflexivos ou não são reflexivos? Os atores são como robôs ou calculadores? Não sei! Nem um nem outro, ou ambos, conforme o momento.

O que é engraçado é que Bourdieu busca exemplos no esporte para embasar sua concepção de senso prático, para mostrar que há muito pouca reflexividade na ação: "Pensem em um jogador de tênis que se move em direção a uma bola que vem a $200 \mathrm{~km} / \mathrm{h}$. Ele não tem tempo de calcular nada, tem o senso do jogo, vai para a esquerda, para a direita, corre, faz os gestos certos sem ter que calculá-los. Deve-se pensar o mundo social como o comportamento de um esportista que acerta na bola no momento certo, que tem a bola no pé ou que salta na hora certa para "cabecear" e marcar o gol". Porém, o que Bourdieu esquece é que, mesmo quando se joga futebol ou tênis, aprende-se a parar e fazer pausas.

Por exemplo, é cada vez mais frequente gravar o treinamento de um tenista; o treinador Ihe mostra depois a gravação, ambos deixam a urgência da prática e objetivam a prática graças ao vídeo. E então, o treinador diz ao tenista: "Você está vendo, aqui não está segurando a raquete do jeito certo. Veja como você fica, não está bom, você não antecipou, na próxima vez precisa pensar em voltar sempre para o meio...". Utilizam-se, portanto, ferramentas como o vídeo para operar uma reflexividade sobre a prática, na própria prática esportiva. 
Sociologias, Porto Alegre, ano 17, no 38, jan/abr 2015, p. 280-302

O exemplo de Bourdieu é o jogo enquanto ocorre, a performance esportiva, mas essa performance é interrompida e se analisa o que aconteceu. Depois de ganhar, esportistas e treinadores geralmente vão primeiro beber, mas no dia seguinte eles se perguntam: "Ah, sim, então por que você ganhou?", e eles analisam. E quando se trata de torneios de futebol, de copas do mundo de futebol, de rúgbi ou de qualquer outra coisa em que há continuidade de jogos, eles analisam cada noite e dizem: "Você não estava ali, devia ter ficado aqui; vocês são lentos demais na defesa, precisam avançar, etc." Eles dão dicas, retomam a prática, e esses momentos rompem com a urgência da prática.

Uso esses exemplos para mostrar que a prática de um esportista é constituída de momentos de performance na urgência, sem reflexividade, mas também de gestos que foram preparados por reflexividade antes da performance. Existem, portanto, momentos de reflexividade, momentos de preparação, de planejamento, momentos de urgência prática e momentos de exame da prática. Acredito que se devem escolher objetos, práticas de indivíduos reais e observá-los, descrevê-los, ver se são reflexivos ou não, avaliar o grau de reflexividade conforme o momento. É isso que se deve fazer, e não é em Giddens que se deve buscar a solução.

P.: E o que o senhor acha do trabalho de François Dubet sobre a condição do indivíduo no período contemporâneo?

B.L.: O problema é que não compreendo realmente o que Dubet diz em Sociologia da Experiência ${ }^{5} .$. Fico muito incomodado, porque, em última instância, isso não merece nenhum comentário particular... Eu me lembro de um esquema que ele utiliza nesse livro e confesso que não entendi. Conheço sua origem (vem de antigos esquemas de Touraine, que eu tinha lido

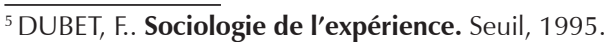

http://dx.doi.org/10.1590/15174522-017003831 
Sociologias, Porto Alegre, ano 17, no 38, jan/abr 2015, p. 280-302

quando era estudante), mas não entendo de verdade. As únicas coisas que compreendo bem, em Dubet, são as pesquisas específicas sobre os jovens ou sobre a escola. A partir disso, posso começar a discutir suas teses. Mas não entendo a teoria da experiência, a parte de reflexividade, os processos de subjetivação, o esquema presente no livro. Não os entendo e, quando consigo entender, acho que ele está enganado... Por exemplo, Dubet faz uma apresentação da sociologia de Norbert Elias, mas eu acho que ele não o entendeu: situa esse autor entre os autores clássicos que partiam da oposição indivíduo/sociedade, ao passo que todo o trabalho de Norbert Elias é uma busca de superar essa oposição. Considero que não há ninguém mais prudente e, ao mesmo tempo, mais radical do que Norbert Elias em relação à ideia de que não se pode dissociar "indivíduo" e "sociedade".

É difícil comentar globalmente um autor, pois isso pode ser muito injusto e violento, mas reprovo muitas coisas em Sociologia da Experiência de Dubet, em sua concepção do ator e da verdade que viria às vezes da boca dos atores. Ele nos diz nesse livro, por exemplo, que devemos submeter uma parte das hipóteses que formulamos aos atores e que, se essas hipóteses forem recusadas por eles, devemos abandoná-las: como diz a expressão popular, "fico de queixo caído!". Se os físicos tivessem pedido às pessoas que dissessem se a Terra é redonda ou plana, talvez a versão oficial ainda fosse "a Terra é plana". Muitos problemas como este deveriam ser discutidos em detalhe, mas isso levaria muito tempo.

P.: Em seus trabalhos, Axel Honneth desenvolve a ideia de que os indivíduos que sofreram uma injustiça se engajam em uma luta por reconhecimento. O senhor poderia falar um pouco sobre isso?

B.L.: Esta é uma verdadeira questão, já que a ideia de não ser reconhecido no que se faz, no que se é, foi um tema que emergiu dos movimentos sociais. Acho que, na França, uma parte dos professores sofre hoje em 
dia uma espécie de falta de reconhecimento. O problema é que tenho a impressão de que, ao menos politicamente, o tema do reconhecimento logo se transforma em um tema conservador. Ao se dizer "Os professores precisam de reconhecimento", vai-se revalorizar simbolicamente sua atividade, vai-se afirmar que é preciso falar melhor dos professores, que é preciso prestar mais atenção neles, etc. Mas com frequência os professores reivindicam mais recursos em aula, menos alunos nas turmas, auxílio psicológico quando necessário, etc. Ouvi um ministro de direita dizer: "O que eles pedem não é mais dinheiro, é atenção". Não! Às vezes, eles querem dinheiro, eles não querem forçosamente só "atenção", ou então querem atenção quando dizem: "Queremos mais dinheiro ou mais recursos".

Não acho que Axel Honneth pense assim, evidentemente, mas na França a temática do reconhecimento pode rapidamente se inscrever em uma lógica de conservação social. Nem todas as reivindicações, nem todas as lutas são lutas pelo reconhecimento da dignidade; acredito que há lutas muito menos simbólicas do que isso.

Dito isso, acho que Axel Honneth e uma parte dos filósofos que seguem a tradição da escola de Frankfurt fazem algo que é bastante interessante para os sociólogos. Eles próprios estão habituados a trabalhar com economistas, sociólogos, às vezes com psicanalistas, e isso é bom. Alguns filósofos sociais franceses gostariam de fazer um trabalho interdisciplinar com pesquisadores das Ciências Sociais, até mesmo participar de pesquisas. Isso é novo para a filosofia francesa, mas não para filósofos como Honneth, porque ele não menospreza absolutamente a investigação empírica. Adorno, em compensação, em uma parte de sua obra, menosprezava as investigações, considerava que a pesquisa empírica tinha a ver com o positivismo; depois, progressivamente, passou a dizer: "Não, a ciência empírica é necessária". Ele melhorou com o tempo então! Mas não posso falar mais sobre o reconhecimento, pois nunca trabalhei com 
Sociologias, Porto Alegre, ano 17, ํo 38, jan/abr 2015, p. 280-302

essas questões: acho apenas que pode ser interessante ver como, nos movimentos sociais, as reivindicações sociais, essas questões de reconhecimento de uma identidade, de um sofrimento particular, de uma situação particular podem ser propostas pelos atores.

Uma última coisa talvez: as palavras "reconhecimento" e "luta por reconhecimento" supõem uma forte dimensão subjetiva. Significam que as pessoas querem reivindicar algo de particular sobre o que elas são. Ora, acho que não se pode reduzir tudo à imagem que as pessoas têm do que são. É mais ou menos o que acontece com a noção de identidade, que me incomoda. É um conceito interessante para situações políticas de reivindicação identitária, para pessoas que dizem, por exemplo, "nós somos gays, e queremos ter os mesmos direitos que os outros", ou "nós somos negros e queremos ser tratados como todo mundo", etc. Mas é um conceito político; de certo modo, é a reivindicação do direito à diferença, ou do direito à indiferença, para dizer "nós existimos e parem de nos estigmatizar, parem de nos tratar mal", etc. Não se pode compreender tudo do mundo social se baseando unicamente nessas reivindicações de identidade. Os homossexuais que reivindicam em uma parada gay são, por outro lado, operários, engenheiros, universitários, e isso contribui amplamente para determinar seus comportamentos. No entanto, não carregam um cartaz com os dizeres "Eu sou um operário gay da fábrica Renault, da terceira geração de imigrantes, etc.". Eles são realmente definidos (no sentido de determinados) por tudo isso, mas só expressam o que é um problema do ponto de vista político. Portanto, há uma dimensão fortemente subjetiva, até mesmo subjetivista, na ideia de identidade.

A noção de reconhecimento que vejo operando na França sofre derivas subjetivistas, como quando se esquece que nem tudo se reduz à representação subjetiva que os atores têm de sua própria situação, tanto mais que essas representações podem variar com o tempo. Pessoas que, 
Sociologias, Porto Alegre, ano 17, no 38, jan/abr 2015, p. 280-302

aos vinte anos, vão às ruas em determinado momento para dizer "nós somos gays" podem muito bem, vinte anos mais tarde, dizer "não preciso ir às ruas, sou gay assim como tenho uma casa, existo assim, e só." Ninguém se levanta toda manhã, dizendo: "Vou reivindicar o que eu sou", e somos muitas "coisas" ao mesmo tempo; definimo-nos por características em planos muito diferentes. Trata-se geralmente de momentos de encenação pública de uma imagem pessoal, ligada a uma defesa de direitos.

P.: Uma questão metodológica: a Sociologia, ao longo de toda sua trajetória, buscou demonstrar e compreender ao mesmo tempo certas tendências de reprodução social ou de mudança social. Mesmo estudos qualitativos com pequenos grupos tinham, entre outros objetivos, a intenção de mostrar e de compreender o que se apresenta como uma certa generalização de comportamento ou de sociabilidade. Ou, ao contrário, a ideia era compreender as tendências de mudança social, ou de diferenciação entre os modos de sociabilidade. Em sua dimensão teórica, a Sociologia indicou razões possíveis para essas regularidades, tendências ou mudanças sociais eventuais. A Sociologia em escala individual que o senhor propõe permite atingir um certo nível de generalização para o grupo estudado? Podem-se compreender assim as tendências de comportamento, constatar certas regularidades ou a emergência de mudanças sociais no mundo atual?

B.L.: Eu não oponho a escala individual do social à macrossociologia, já que essa escala individual do social, esta análise das disposições, sobretudo dos patrimônios de disposições individuais, supõe se apoiar no conhecimento dos trabalhos sobre as instituições escolares, os universos profissionais, as instituições religiosas, culturais, políticas, esportivas, etc., que formaram os indivíduos em questão. Para mim, não há essa oposição. Acredito que se pode compreender melhor certos fenômenos macrossociológicos, observando de perto o comportamento de indivíduos. 
Foi o que fez, em uma perspectiva bem diferente, o historiador Carlo Ginzburg em $O$ Queijo e os Vermes ${ }^{6}$. Ele trabalhou sobre a história de um moleiro no Friul italiano do século XVI, Menocchio. Escolhe um caso particular e, por meio dele, é levado a falar do funcionamento da Inquisição na época, das instituições religiosas, das relações entre cultura popular e cultura erudita, dos processos de bruxaria, já que Menocchio vai ser queimado porque afirma que Deus não existe como se imagina, e assim por diante. Trabalhar em um caso particular pode oportunizar um trabalho sobre todo um contexto social. Quando se lê a biografia histórica de São Luís, escrita por Jacques Le Goff', não se aprendem somente coisas sobre São Luís. Por meio dele, toma-se conhecimento de quase toda uma época, todo um funcionamento coletivo. Poder-se-ia dizer a mesma coisa acerca de Bourdieu: quando ele se volta para Flaubert ${ }^{8}$, também busca compreender o estado do campo literário na época.

Se a pergunta é "a análise de um indivíduo permite generalizar toda uma época, todo um contexto?", a resposta é evidentemente não. Há um problema de representatividade estatística: pode-se dizer que um indivíduo ocupa uma posição em um universo, mas outra coisa é afirmar que é possível, através da análise de um indivíduo em determinado contexto, captar toda a lógica de uma época. Por exemplo, eu trabalhei sobre Kafka, mas não posso dizer que falo dos escritores em geral, nem mesmo posso dizer que, por meio dele, afirmo o que é a literatura em Praga na época, isso não é possível. Em contrapartida, graças à análise do caso

\footnotetext{
${ }^{6}$ GINZBURG, C.. Le fromage et les vers : L'univers d'un meunier du XVle siècle. Flammarion, coll. Nouvelle bibliothèque scientifique, 1980. GINZBURG, Carlo. O Queijo e os Vermes; o cotidiano de um moleiro perseguido pela inquisição. São Paulo, Companhia das Letras, 2006.

${ }^{7}$ LE GOFF, J.. Saint Louis. Gallimard, coll. Bibliothèque des histoires, 1996.

${ }^{8}$ BOURDIEU, P.. Les règles de l'art. Seuil, 1992. BOURDIEU, P. As Regras da Arte: Gênese e Estrutura do Campo Literário. Trad. Maria Lúcia Machado. São Paulo: Companhia das Letras, 1996.
} 
Sociologias, Porto Alegre, ano 17, no 38, jan/abr 2015, p. 280-302

de Kafka, sou obrigado a reconstruir o contexto literário do período e, portanto, contar com elementos muito mais amplos de compreensão. Por exemplo, em seus textos, Kafka faz oposições entre o Leste e o Oeste, entre o Oriente e o Ocidente. Quem não conhece a problemática política da época, que faz com que, para os judeus de Praga, os judeus do Leste sejam melhores do que os outros porque conservaram suas tradições, não compreende as referências implícitas que este autor faz a essas oposições em sua literatura. Sou obrigado a abranger elementos muito amplos de contextualização política, ideológica e cultural da época para abranger elementos de sua obra. Mas não posso dizer que estudo um caso e que ele é generalizável a todos os escritores, isso evidentemente não tem sentido. O que é generalizável, em compensação, é o modelo que construo para articular contextos, biografia sociológica e obra literária.

P.: Pode-se então dizer que essa generalização depende das escolhas teóricas do sociólogo, que nortearão a reconstrução do contexto?

B.L.: Sim, dependendo do que se quer explicar, do que se quer compreender, não se vai reconstruir o mesmo contexto. Se quero compreender por que Kafka estudou Direito, sou obrigado a considerar sua vida familiar, sua relação com a escola, a posição do Direito em relação às outras disciplinas, etc. Foi o que fiz, e não precisei reconstruir outros elementos do contexto. Agora, se eu quiser compreender sua criação literária, é mais complicado: devo compreender ao mesmo tempo o cenário familiar, o cenário escolar, sua relação com os estudos, sua formação jurídica, sua formação religiosa... Todos esses elementos têm efeitos sobre sua obra, mas vou selecionar os contextos em função dos elementos que busco compreender. 
Sociologias, Porto Alegre, ano 17, o 38, jan/abr 2015, p. 280-302

P.: No livro L'esprit sociologique ${ }^{9}$, o senhor evoca cinco lugares-comuns relativos à metáfora da construção social da realidade. O senhor poderia retomar essas interpretações contestáveis e nos explicar por que todo sociólogo deve se precaver contra esses lugares-comuns?

B.L.: A expressão "construção social da realidade" é bastante instigante para os estudantes de Sociologia. Eu fui estudante de Sociologia e sei o que isso causa! Fala-se de construção social do gênero, de construção social da moeda, de construção social do tempo, de construção social de tudo... $\mathrm{E}$ isso tem inegavelmente um efeito desnaturalizante em relação ao que geralmente se considera uma realidade evidente, natural: por exemplo, quando os economistas falam de mercado, tem-se a impressão de que se trata da natureza, "a natureza é a selva, isso é bem conhecido, e a selva é o mercado, que supostamente sempre existiu". A ideia de construção social da realidade permite, então, ressituar a história na percepção das coisas e dizer que a realidade é o produto da história. Foram homens que fizeram coisas para que se chegasse aqui e se pode agir para que as coisas sejam diferentes.

Porém, o problema é que uma vez dito isso, logo vão surgir usos desviados da ideia de construção social da realidade, que me parecem muito problemáticos. Em primeiro lugar, um dos lugares-comuns que me vem à mente é considerar que o "social" é "simbólico", isto é, que a construção social da realidade não passaria de uma construção discursiva. Houve leituras assim de Foucault: "vamos identificar todos os discursos que recortam a realidade, que apresentam a realidade de um certo modo". O problema é que a construção da realidade social não é apenas simbólica, ela também é material, está em objetos, instituições, textos; existem "coisas" que não

${ }^{9}$ LAHIRE, B.. L'esprit sociologique. Paris, La Découverte, coll. Textes à I'appui/Laboratoire des sciences sociales, 2005. 
Sociologias, Porto Alegre, ano 17, no 38, jan/abr 2015, p. 280-302

são simplesmente realidades simbólicas. Isso permite desvios: chega-se à conclusão de que são os atores que constroem essa realidade socialmente, e até mesmo discursivamente, e que, caso se queria estudar a construção social da realidade, será preciso estudar unicamente as representações que os atores têm delas. Assiste-se então a uma espécie de abdicação da ciência, como se só se pudesse analisar a experiência subjetiva que os atores têm da realidade. Não posso mais, nesse momento, dizer que os atores "se enganam" ou que os atores têm a ilusão de que isso acontece assim, mas que eu, sociólogo, quando estudo a realidade, vejo que elas não se dão assim. Se houver seriedade no trabalho, não se pode reduzir a construção social da realidade a uma construção dos atores e das representações que eles têm dela. Existem coisas que restringem a ação dos atores, que são externas a eles e das quais eles nem sempre têm consciência.

Não lembro mais dos outros lugares-comuns, mas há muitos desvios como esse. Por exemplo, há uma ideia recorrente entre os interacionistas e os antropólogos: a realidade não está dada de uma vez por todas, como se não houvesse estruturas e como se reconstruíssemos a realidade a todo o momento. Cada vez que nos encontrássemos, na vida, surgiria a questão da redefinição da situação social, como se a realidade social precisasse ser permanentemente reconstruída pelos atores. Ora, o que lembro simplesmente em meu texto é que, quando nos levantamos pela manhã, não inventamos nossa língua, a instituição do casamento, o direito, a moeda, etc. Lidamos com todas essas instituições que se impõem a nós. Compreende-se então um pouco melhor o que Durkheim quer dizer quando afirma que "o social é coercitivo". Eu não escolhi nascer em uma sociedade capitalista: nasci em 1963 nesta sociedade, e numa sociedade francesa, e não africana, ou asiática... Portanto, são as instituições de minha época, de minha sociedade, de meu grupo social, e assim por diante, que se impõem a mim. Quando levamos a crer com a ideia de 
Sociologias, Porto Alegre, ano 17, o 38, jan/abr 2015, p. 280-302

construção social que, se isso se constrói, então se desconstrói facilmente, e que se constrói diariamente como efeito da intencionalidade dos atores, enganamo-nos completamente.

Em primeiro lugar, não é a intencionalidade dos atores que está em jogo: se uma manhã você decide que o sistema capitalista não existe, isso pode ser muito bom para você, mas se continuar pensando assim vai ser internado num hospital psiquiátrico, ou será levado a compreender que deve dar dinheiro pelas mercadorias que pegou numa loja. Fazendo isso, vai ser relembrado das realidades ordinárias do capitalismo, o que prova que muitas coisas se impõem a você.

Em segundo lugar, para transformar o que foi construído, é preciso muito trabalho e energia. Uma expressão como a "construção social da realidade" dá uma impressão de leviandade e acarreta uma espécie de liberação política. A gente pensa que, se tal coisa foi construída, então se pode desconstruí-la. Desconstruamos o capitalismo! Mas isso é difícil para os militantes: como se desconstrói o capitalismo? Por onde se começa? É preciso tomar os bancos? Devem-se suspender as empresas? O que se deve fazer? No entanto, muitos sofrem com o capitalismo. Se fosse tão fácil desconstruir algo como o capitalismo, isso já teria sido feito há muito. É claro que existem coisas mais fáceis de desconstruir e reconstruir, mas o social se impõe frequentemente como um estado de fato quase natural. $\mathrm{Na}$ escala de uma biografia, às vezes acho mais realistas as pessoas de meios populares, que dizem "sempre existiram ricos, sempre existiram pobres", do que o militante que diz: "não, isso não é verdade, podemos mudar...". Francamente, não creio ver o fim do capitalismo antes de morrer, mesmo que eu morra com a idade de Lévi-Strauss! [risos] Acredito que o capitalismo existirá sempre, pelo menos com toda probabilidade. A instituição do casamento talvez possa desaparecer, ou a língua francesa, estamos tão dominados pelo inglês... Mas a maioria das instituições dura, 
Sociologias, Porto Alegre, ano 17, no 38, jan/abr 2015, p. 280-302

perdura por vários séculos, às vezes, por milênios. Para compreender o capitalismo hoje, é preciso retroceder várias centenas de anos de lógica econômica, estatal, etc., que contribuíram para construí-lo.

Por todas essas razões, considero que a ideia de construção social da realidade é muito útil para pensar a realidade como produto da história, mas devemos desconfiar de certos usos descuidados dessa expressão.

P.: Por fim, o que o senhor acha da sociologia brasileira?

B.L.: É impossível responder a essa pergunta. Primeiro, porque há tantos trabalhos sendo feitos no Brasil que é muito difícil apreender a "sociologia brasileira" em sua totalidade. Faz quinze anos que encontro sociólogos brasileiros e compreendo um pouco melhor o que se faz, mas é muito difícil ter uma opinião fechada, definitiva, sobre a "sociologia brasileira". O que posso dizer é que é uma sociologia em bom estado, em evolução, principalmente graças a universidades que se encontram em uma fase muito mais dinâmica do que as do Velho Continente. As universidades brasileiras têm mais recursos, e surgem novas por toda parte. Seria bom ter isso na França e poder se alegrar com a abertura de novas universidades, mas tudo isso já passou.

Vejo então, no Brasil, um meio muito mais dinâmico, muito mais entusiasta, muito menos pessimista, porque acredito que a universidade no Brasil está em pleno crescimento, com recursos financeiros, com estudantes com sede de aprender, etc. Venho regularmente ao país, justamente porque é instigante. É uma maneira de suportar onze meses de desânimo francês, com pessoas, das quais faço parte, que passam o tempo todo se queixando da situação [risos] ${ }^{10}$.

\footnotetext{
${ }^{10}$ No momento desta entrevista, em novembro de 2011, o presidente da França ainda era Nicolas Sarkozy.
} 
Sociologias, Porto Alegre, ano 17, oo 38, jan/abr 2015, p. 280-302

P.: E como o senhor vê a relação franco-brasileira no campo da sociologia?

B.L.: Teríamos evidentemente um grande interesse em fazer sociologia em comum, mas já acontecem algumas trocas: muitos sociólogos brasileiros vão à França, fizeram seu doutorado ou pós-doutorado lá... Essas viagens oferecem aos brasileiros, primeiramente, a possibilidade de conhecerem a realidade francesa, no caso dos que fazem teses sobre a França. Mas eles também podem buscar elementos de cultura científica, metodológica ou teórica para ver como podem ser empregados no Brasil. Frequentemente explico que os conceitos são carregados de história, de cultura. As teorias sociológicas francesas são marcadas pela história francesa, sem que se tenha consciência disso. Muitas vezes, é o produto de uma história muito francesa, ou europeia, que está cristalizado nos conceitos dos sociólogos franceses. Ora, o interesse desse intercâmbio entre franceses e brasileiros é perceber que nem tudo funciona, que não é bem a mesma coisa, que não faz sentido falar do mesmo modo, por exemplo, de "distinção cultural" no Brasil e na França. Ainda não compreendi totalmente o conjunto das dinâmicas culturais que constituem a realidade brasileira. Sei que há processos de distinção cultural muito próximos das dinâmicas européias - a grande música clássica, por exemplo -, mas sei também que existem outras especificidades culturais que originam processos diferentes. Então, seria preciso fazer análises comparativas e, cada vez, adaptar os conceitos utilizados para estudar a realidade francesa ou europeia a uma realidade brasileira. Os conceitos são históricos: quando são criados em certos países, ficam marcados pela experiência desses países.

Uma de minhas obras que foi bem aceita no Brasil, Tableaux de famille ${ }^{11}$, trata do sucesso escolar das crianças em meios populares. É uma problemática que evidentemente interessa muito as Ciências da Educação

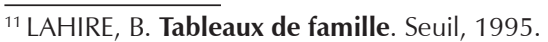


Sociologias, Porto Alegre, ano 17, no 38, jan/abr 2015, p. 280-302

ou a Sociologia da Educação no Brasil, país em que o sucesso das crianças das favelas é uma questão política importante. No entanto, sempre digo a meus colegas brasileiros: "Quando vocês dizem classes populares, e quando eu digo classes populares, não é a mesma coisa, temos as mesmas palavras para designar realidades que não têm nada a ver." As condições de vida dos operários franceses nos anos 1990, na França, não têm nada a ver com as condições de vida das pessoas que vivem em favelas, não são as mesmas condições de moradia, o mesmo sistema de proteção social, a mesma relação com a saúde, com a escola, etc. Do mesmo modo, quando falo de escola primária na França e de escola primária no Brasil, todo mundo acha que está falando da mesma coisa, mas os alunos do segundo ano do curso elementar que eu estudo têm aulas em turno integral, ao passo que os daqui vão à escola somente um turno, têm professores que são mal pagos, que acumulam cargos e que nem sempre são muito bem formados. Como as realidades não são as mesmas, podemos nos equivocar com as palavras, com o que há por trás das palavras. Acredito que precisamos desconfiar do colonialismo conceitual. Se chego com minha teoria e quero aplicá-la ao Brasil, isso não funciona, é necessário sempre compreender as realidades locais, adaptar os conceitos, etc. Isso não impede que os problemas que levanto sobre a França possam ser levantados para o Brasil, desde que adaptados e bem formulados. Temos então todo interesse em continuar, em intensificar as trocas, e espero que haja muitas bolsas no futuro para os estudantes que quiserem descobrir outro mundo (social e científico).

\section{Referências}

1. BOURDiEU, P. As Regras da Arte: Gênese e Estrutura do Campo Literário. Trad. Maria Lúcia Machado. São Paulo: Companhia das Letras, 1996.

2. BOURDIEU, P.. Les règles de l'art. Seuil, 1992.

3. DUBET, F.. Sociologie de l'expérience. Seuil, 1995. 
Sociologias, Porto Alegre, ano 17, no 38, jan/abr 2015, p. 280-302

4. GINZBURG, C.. Le fromage et les vers: L'univers d'un meunier du XVle siècle. Flammarion, coll. Nouvelle bibliothèque scientifique, 1980.

5. GINZBURG, Carlo. O Queijo e os Vermes; o cotidiano de um moleiro perseguido pela inquisição. São Paulo, Companhia das Letras, 2006.

6. LAHIRE, B.. Franz Kafka. Eléments pour une théorie de la création littéraire. Paris: La Découverte, Textes à l'appui/Laboratoire des sciences sociales, 2010.

7. LAHIRE, B.. L'esprit sociologique. Paris, La Découverte, coll. Textes à l'appui/ Laboratoire des sciences sociales, 2005.

8. LAHIRE, B.. L'homme pluriel. Les ressorts de I'action. Nathan, coll. Essais \& Recherches, Sciences sociales, 1998.

9. LAHIRE, B.. Le travail sociologique de Pierre Bourdieu. La Découverte, coll. "Poche", 2001.

10. LAHIRE, Bernard. Homem plural: os determinantes da ação. Tradução de: Jaime A. Clasen. Petrópolis: Vozes, 2002.

11. LAHIRE, B. Tableaux de famille. Seuil, 1995.

12. LATOUR, Bruno; WOOLGAR, Steve. A vida de laboratório: a produção dos fatos científicos. (Trad. Angela R. Vianna) Rio de Janeiro: Relume Dumará. 1988.

13. LATOUR, B. ; WOOLGAR, S. (1979). La vie de laboratoire. La production des faits scientifiques, rééd. La Découverte, coll. "Poche", 2006.

14. LE GOFF, J.. Saint Louis. Gallimard, coll. Bibliothèque des histoires, 1996.

Recebido em: 03/09/2014

Aceite Final: 05/10/2014 